\title{
LÓGICA E ESPAÇO NA OBRA DE IMMANUEL KANT E SUAS IMPLICAÇÕES NA CIÊNCIA GEOGRÁFICA*
}

\author{
ÉLVIO RODRIGUES MARTINS \\ Universidade de São Paulo
}

Armando Corrêa da Silva havia afirmado que a ciência geográfica estava presa a um "impasse aristotélico-kantiano"(SILVA, 1996), onde o fundamento lógico seria a lógica formal (Aristóteles) e a concepção de espaço advinda de Kant. Este trabalho busca não só apresentar a concepção de espaço em Kant, em diferentes momentos de sua obra, bem como o quanto era absolutamente estrutural no seu pensamento a concepção de espaço, além de verificar uma estreita coerência entre sistema lógico e concepção de espaço. Com isso permitimos uma melhor visualização da influência deste filósofo na constituição da ciência geográfica.

Em relação à Lógica, é possível observar marcas da influência do trabalho de Aristóteles na obra de Kant. Ocorre que esta herança não se dá sem uma significativa alteração. Tais alterações referem-se exatamente a diferenças que vão ao encontro da posição que ocupam espaço e tempo dentro do sistema lógico. Para a compreensão do que está sendo afirmado, é necessário que tenhamos de proceder a uma circunstanciação da questão e, mediante isto, desdobrá-la em eventuais conclusões. Ou seja, necessitamos estabelecer a relação da Lógica com a discussão entre espaço e tempo.

\footnotetext{
* Este texto é parte do capítulo 1 da tese de doutorado de título Da Geografia à Ciência e o Discurso Teórico, defendida em 1977 na USP sob a orientação de Armando Correa da Silva.
} 
Ao nosso ver as questões referentes ao espaço e ao tempo em Kant ocupam uma posição das mais destacadas ao longo de sua obra. Entre outros trabalhos, de que necessitamos expor as idéias fundamentais, está a Crítica da Razão Pura, escrito em duas "versões": uma de 1781 e outra de $1787^{\prime}$. Contudo, a relevância dada ao espaço e ao tempo já é sentida desde o primeiro trabalho da sua assim chamada fase "précrítica". A esta fase registramos, especialmente, dois trabalhos, onde Kant apresenta suas idéias referindo-se diretamente à importância do espaço e do tempo: o primeiro, de 1768, denominado Em torno do Primeiro Fundamento da Distinção das Regiões do Espaço, e um segundo, datado de 1770, chamado Acerca da Forma e dos Princípios do Mundo Sensível e Inteligivel, também conhecido como a Dissertação de 1770.

No trabalho de 1768, encontramos o filósofo preocupado em construir uma prova evidente, presente nos juízos intuitivos relativos à extensão, da existência de um espaço absoluto, ou seja, um espaço que seja independente da existência de toda a matéria, admitindo-lhe, com isto, uma realidade própria.

Uma das afirmações preliminares neste trabalho nos parece de grande importância:

"Com efeito a situação das partes do espaço em suas relações recíprocas pressupõe a região de acordo com a qual elas estão ordenadas segundo uma tal relação, e, no sentido mais abstrato, a região não consiste, na relação no espaço de uma coisa com uma outra - o que, rigorosamente falando, é o conceito de situação-, mas na relação do sistema destas situações com o espaço absoluto do universo."(KANT, 1983, p.167)

Mais adiante, Kant considera que qualquer que seja a coisa extensa, podemos tomar conhecimento da situação das partes umas em relação às outras, a partir delas mesmas. Entretanto, no tocante à região em que esta ordem das partes se orienta, relaciona-se com um espaço exterior às coisas e de forma alguma com as posições que elas ocupam.

“A região não seria mais do que a situação das mesmas partes, sob o ponto de vista de uma relação exterior, mas considerando o espaço comum enquanto unidade, de que aquela extensão deve ser considerada como uma parte."(KANT, 1983, p.168)

Região parte. Espaço todo. Sendo que as coisas situadas na região não se confundem com estas partes do espaço, estando apenas situadas nelas respectivamente.

\footnotetext{
'Acerca destas duas "versōes", registra-se uma polêmica entre os comentadores do pensamento de Kant, quanto ao fato de existirem diferenças significativas nas duas versões. A nosso ver ficamos com os partidários da tese de que, a segunda, em relação à primeira, representa um amadurecimento do autor, e, portanto, esforço de tornar mais enfáticas e claras as passagens mais importantes do seu trabalho.
} 
Kant estabelece a importância das regiões do espaço, mediante a ilustração do nosso próprio corpo. Diz ele, que partindo do nosso corpo podemos estabelecer três planos perpendiculares entre si. Isto em virtude da sua tridimensionalidade. E acrescenta que, "uma vez que não podemos conhecer tudo o que está fora de nós através dos sentidos a não ser na medida em que estiver em relação conosco", seria em função de tal fato que tiraríamos destes três planos em interseç̧ão com o nosso corpo os elementos primários que constituiriam o conceito de regiões do espaço.

Deduz daí a existência de um plano horizontal, que nos atinge perpendicularmente em relação ao nosso comprimento, e mediante isto é possível definir as regiões "alta" e "baixa". Dois outros planos podem cruzar este último de forma perpendicular, onde um definiria as regiões "esquerda" e "direita" e o outro as regiões referentes "à frente"e "atrás".

Da mesma forma diríamos de uma folha escrita, onde teremos o "alto"e o "baixo" da escrita, além também da diferença do "verso" e do "reverso". Pode-se ainda, em relação às linhas, dizer sobre sua situação da direita para a esquerda e o inverso. Assegura-se, em função disto, que independente de como viremos a folha, sempre teremos que a situação das partes ordenadas sobre a superfície sempre será a mesma, tanto quanto a situação destas mesmas partes umas em relação às outras. Mas, Kant ressalva que

“(...) a diferença entre as regiões entra de tal forma em linha de conta e está de tal forma ligada à impressão produzida pelo visível, que o que está escrito, visto de outra maneira, tudo o que ocupava antes uma determinada região encontra-se agora orientado no sentido da região oposta."(KANT, 1983, p.169)

O que leva o filósofo a afirmar que, mesmo os nossos juízos sobre as regiões do espaço são subordinados ao conceito que temos de regiões em geral. Ou seja, da determinação destas regiões pelas suas relações com os lados do nosso corpo.

"Passa-se exatamente o mesmo com o conhecimento geográfico e até com o conhecimento mais vulgar da situação dos lugares: não nos serve para nada se não pudermos determinar as coisas ordenadas desta maneira e todo o sistema de relações recíprocas de acordo com as relações com os lados do nosso corpo segundo as regiões.”(KANT, 1983, p.170)

Disso tudo, Kant quer demonstrar que o fundamento da determinação da forma corporal não está exclusivamente na relação e na situação das suas partes umas com as outras, mas, também, principalmente, na situação que mantém com o espaço absoluto em geral. Seria este, inclusive, o fundamento único onde se distinguem as diferenças do corpo.

No sustentar desta posição, nos apresenta uma série de exemplos, especialmente o do reflexo de uma mão em um espelho, admitindo com isto que, corpos perfeitamente iguais e idênticos, nem sempre podem ser encerrados nos mesmos limites. Oú seja, o reflexo da mão direita é a esquerda e vice -versa e, portanto, tem-se: 
"Dado que a superfície que limita o espaço corporal de um corpo, se o virarmos e o voltarmos a virar como nos apetecer, não pode servir de limite ao segundo, esta diferença deve ser de tal espécie que possua um fundamento interno. Mas este fundamento interno da diversidade não poderia ser tomado por conta de uma diferente disposição na ligação das partes do corpo umas em relação às outras, pois, de acordo com os exemplos citados, tudo pode ser a este respeito, perfeitamente idêntico. De tal forma que, se consideramos que a primeira criatura é uma mão de homem, é necessário que esta seja esquerda ou direita e, para criar a primeira, a operação da causa criadora terá de ser necessariamente diferente daquela pela qual poderia ser perfeita a sua réplica."(KANT, 1983, p.173)

O que temos na verdade aqui, é a indisposição de Kant em relação ao fundamento da hipótese de Leibniz sobre a "congruência". Este último filósofo procura desenvolver uma geometria sem figuras, baseada exclusivamente em pontos. Ou seja, segundo Leibniz estabelecer-se-ia um sistema determinado de sítios, em que um ponto está situado na medida em que se relaciona com outro. E um sítio é definido pela distância em função de outro e pela congruência, pois dois pontos são possíveis de serem sobrepostos. Isto eliminaria a noção de extensão neste tipo de geometria.

Kant parte exatamente da incongruência possível entre dois objetos. E aí nos apresenta o exemplo das duas mãos. Este caso é para Kant a prova de que o espaço não é apenas uma ordem de coexistência, pois, no exemplo dado, trata-se de figuras simétricas, sendo que, entretanto, não admitem a superposição congruente.

Esta situação leva-o a negar a tese de que o espaço consiste apenas nas relações exteriores das partes coexistentes da matéria, pois não existe , como no caso da mão esquerda em relação à direita, diferenças nas relações das suas partes constitutivas. Admitir esta tese, equivaleria a concluir que tal propriedade, o espaço, seria completamente indeterminada, ou seja, poderia convir a todas as partes do corpo, e isto é impossível para o filósofo. E, portanto, conclui que:

\begin{abstract}
"De tudo isto, fica claro que as determinações do espaço não são consequências das situações das partes da matéria em relação às outras, mas são estas que são consequências daquelas; que, na estrutura dos corpos encontrar diferenças e mesmo verdadeiras diferenças que se relacionem unicamente com um espaço absoluto e originário, pois só ele torna possível a relação das coisas corporais, e que, visto que o espaço absoluto não é objeto de uma sensação exterior, mas um conceito fundamental que, antes de mais, lhe condiciona a possibilidade, não nos podemos aperceber do que, na forma de um corpo, diz somente respeito à sua relação com o espaço puro, a não ser através da sua oposição simétrica com outros corpos."(KANT, 1983, p. 174)
\end{abstract}

No segundo trabalho (de 1770), Kant já se indaga sobre a existência de um princípio substancial que justifique a ordem das coisas existentes no mundo, isto do ponto de vista do espaço e do tempo. E, neste sentido, quando o sujeito, através do seu intelecto é impressionado pelos objetos exteriores, possui as condições desta 
percepção, porque o princípio que dá a ordem espaço-temporal das coisas no mundo encontra-se presente também em sua mente. Mais tarde veremos que Kant chama este princípio de "transcendental".

De toda a sorte, o período "crítico" se inaugura com esta Dissertação de 1770. A designação "crítico" refere-se ao fato de Kant se indispor com as posições assumidas pelos filósofos que o antecederam, especialmente as posições defendidas pela metafísica dogmática, representadas pelo empirismo e pelo racionalismo da época. A primeira defendia que o conhecimento dava-se como uma simples ação das coisas sobre nós, e a segunda advogava a tese de que era possível o conhecimento mediante a existência de uma "harmonia preestabelecida" entre sujeito e objeto, quando as leis do pensamento se identificavam aprioristicamente com aquelas da realidade exterior.

Uma outra posição que nosso filósofo se indispunha, era o ceticismo de Hume. Para este, o conhecimento da coisa em-si era definitivamente impossível, pelo simples fato de que ao se tomar conhecimento das coisas, tais coisas deixam de ser $\mathrm{em}$ si e passam a ser para-nós. Dissolvia-se, portanto, a essência das coisa em-si no apreensão dos objetos pelo intelecto.

Portanto, Kant passa a desenvolver outro caminho em contraposição a estas teses defendidas em sua época, esforçando-se para permitir à razão ter medida de verdade em relação aos aspectos objetivos da realidade. Sem o que, nenhuma çiência seria possível.

Posto em contato com a tese dos "apriorismos" da filosofia racionalista de Leibniz, e observando, simultaneamente, a certeza posta na realidade objetiva pelos empiristas, Kant operou um cruzamento das argumentações. Dispôs o conhecimento como uma síntese entre a matéria como um dado a posteriori (entregue ao sujeito pela experiência), que se dispõe à mente mediante nexos necessários e, portanto, universais, presentes aprioristicamente na razão. Portanto, a certeza da verdade, estará nestes elementos a priori presentes na razão.

Entretanto, o que Kant designa como elementos apriorísticos, não coincide com uma espécie de classe de conhecimentos a priori, como faria por afirmar o racionalismo de sua época.

\footnotetext{
“Assim, na ordem do tempo, nenhum conhecimento precede em nós a experiência e é com esta que todo o conhecimento tem o seu início."(KANT, 1985, 36)
}

Portanto, o que se preocupa em destacar são apenas os elementos do conhecimento que são necessariamente a priori. São estes elementos, que exatamente Kant designará como elementos transcendentais. Ou seja, aqueles aspectos que são constitutivos da experiência, que lhe dá forma, e que mediante a análise revelar-se-ão não serem derivados da experiência, e sim elementos apriorísticos pertencentes à razão.

E assim chegamos à Crítica da Razão Pura. É neste trabalho que o filósofo fará o esforço de mostrar este procedimento gnosiológico que deve a razão percorrer para ter a certeza da verdade. Vejamos. 
$\mathrm{Na}$ introdução desta obra, desenvolvem-se aspectos extremamente importantes para a seqüência do que será verificado.

\begin{abstract}
"Em todos os juízos, nos quais se pensa a relação entre um sujeito e um predicado (apenas considero os juízos afirmativos, porque é fácil depois a aplicação aos negativos), esta relação é possível de dois modos. Ou o predicado B pertence ao sujeito A como algo que está contido (implicitamente) nesse conceito A, ou B está totalmente fora do conceito A, embora em ligação com ele. No primeiro caso chamo de analítico ao juízo, no segundo, sintético. Portanto, os juízos (os afirmativos) são analíticos. quando a ligação do sujeito com o predicado é pensada por identidade; aqueles, porém, em que esta ligação é pensada sem identidade, deverão chamar-se juízos sintéticos. Os primeiros poderiam igualmente denominar-se juízos explicativos; os segundos, juízos extensivos porque naqueles o predicado nada acrescenta ao conceito do sujeito e apenas pela análise o decompõe nos conceitos parciais, que já estavam pensados (embora confusamente); ao passo que os outros juízos, pelo contrário, acrescentam ao conceito um predicado que nele não estava pensado e dele não se podia ser extraído por qualquer decomposição."(KANT, 1985, p.42-3)
\end{abstract}

A primeira série de juízos, os analíticos, constituem-se dados universais e necessários, portanto, dando-nos a certeza da verdade, entretanto sem nada acrescentar ao conhecimento. Já os segundos acrescentam aspectos novos ao conhecimento, pela adesão de predicados novos ao conceito, sendo, porém, afirmações contingenciais e particulares, tanto quanto a experiência de que derivam. Assim, destes segundos nada sabemos ao certo quanto a sua validade universal, ou seja se são verdadeiros ou não. É evidente, que para o filósofo a verdade é um dado universal.

Diante destas circunstâncias, que aspectos deve procurar a razão para que possa superar este impasse e ampliar seu conhecimento sobre as coisas derivadas da experiência? Para isto, Kant verifica a existência de um outro tipo de proposição, cuja razão percebe como verdadeira, possui um caráter sintético, porém não deriva da experiência. A estes juízos denominou juízos sintéticos a priori.

Tais juízos sintéticos a priori, são dados ao conhecimento mediante princípios transcendentais, permitindo a segurança da construção de conhecimentos necessários e universais, portanto, verdadeiros.

$\mathrm{O}$ que Kant tinha em mente (e recorria como prova de suas teses), eram a Matemática e a Física. Estas duas ciências, segundo escreve, são portadoras de juízos sintéticos a priori. E, mediante isto, estende esta necessidade até a metafísica, com o que considera:

"Na metafísica, mesmo considerada apenas como uma ciência até agora simplesmente em esboço, mas que a natureza da razão humana torna indispensável, deve haver juízos sintéticos a priori; por isso, de modo algum se trata nessa ciência de simplesmente decompor os conceitos, que formamos a priori acerca das coisas, para os explicar analiticamente; o que pretendemos, pelo contrário, é alargar o nosso conhecimento a priori, para o que temos de nos servir de 
princípios capazes de acrescentar ao conceito dado alguma coisa que nele não está contida e, mediante juízos sintéticos a priori, chegar tão longe que nem a própria experiência nos possa acompanhar. Isso ocorre, por exemplo, na proposição: o mundo tem de ter um primeiro começo, etc. Assim, a metafísica, pelo menos em relação aos seus fins, consiste em puras proposições sintéticas a priori.(KANT, 1985, p.48-9)

Tratava-se, portanto, de transpor, para a metafísica os rigores científicos da física e da matemática. Ou seja, dever-se-ia dispor a metafísica de juízos necessários e universais, decorrentes da ampliação dos conhecimentos a partir de proposições sintéticas a priori.

Mas, o problema consiste em: como alcançar tais juízos? Ou seja, como é possível fazer da metafísica uma ciência, dotada de juízos sintéticos a priori, possibilitando o uso puro da razão? Isto permitiria aplicá-la às ciências que possuem as prerrogativas necessárias e universais. Teríamos, diante disto, uma matemática pura ou uma física pura.

Assim, a propedêutica necessária estaria exposta na Crítica da Razão Pura, ou, como Kant também denominou, a Filosofia Transcendental.

“A filosofia transcendental é a idéia de uma ciência para a qual a crítica da razão pura deverá esboçar arquitetonicamente o plano total, isto é, a partir de princípios, com plena garantia de perfeição e solidez de todas as partes que constituem esse edifício. É o sistema de todos os princípios da razão pura. Se esta crítica já não se denomina filosofia transcendental é apenas porque, para ser um sistema completo, deveria conter uma análise pormenorizada de todo o conhecimento humano a priori. É certo que a nossa crítica deverá apresentar uma enumeração completa e todos os conceitos fundamentais, que constituem esse conhecimento puro."(KANT, 1985 , p.54-5)

A partir disto, Kant afirma que as fontes do conhecimento humano são derivadas de duas vertentes, ambas originárias de um mesmo tronco comum, que para nós, segundo suas considerações na introdução à "Crítica", é desconhecida quanto esta origem comum. São elas: a sensibilidade e o entendimento. Na primeira, verifica-se a possibilidade de termos os objetos ou elementos. Já na segunda é onde eles (os objetos, elementos), são pensados. Uma vez que a sensibilidade deve conter propriedades a priori, mediante as quais os elementos não se apresentam a nós como um "caos fenomênico", esta deverá pertencer à filosofia transcendental ou Doutrina Transcendental dos Elementos. Do entendimento, Kant, construirá a Doutrina do Método da Crítica da Razão Pura.

Na Doutrina Transcendental dos Elementos, encontramos a primeira seção intitulada Estética Transcendental. Aqui, Kant nos põe em contato com os aspectos que permitem a apreensão primeira dos objetos. Fala da intuição, como sendo a

\footnotetext{
${ }^{2}$ Denominaremos assim, a partir daqui, a obra "Crítica da Razão Pura".
} 
maneira de relacionamento imediato em que o sujeito estabelece com as coisas externas no mundo. Entretanto, esta intuição só se verifica caso o observado venha a afetar o espírito, onde a capacidade de receber representações denomina-se sensibilidade.

\begin{abstract}
"Por intermédio, pois, da sensibilidade são-nos dados objetos e só ela nos fornece intuições; mas é o entendimento que pensa esses objetos e é dele que provêm os conceitos. Contudo, o pensamento tem sempre que referir-se, finalmente, a intuições, quer diretamente, quer por rodeios, e, por conseguinte, no que respeita a nós, por via da sensibilidade, porque de outro modo nenhum objeto nos pode ser dado."(KANT, 1985, p.61)
\end{abstract}

Do efeito produzido por um objeto sobre a capacidade representativa, chama-se sensação. Da intuição que se relaciona com o objeto, através da sensação, denomina-se empírica. E do objeto indiferente de uma sensação empírica, dá-se o nome de fenômeno.

Dispondo desta maneira os diversos elementos da estética transcendental, o filósofo dá outros elementos extremamente importantes:

"Dou o nome de <matéria〉> ao que no fenômeno corresponde à sensação; ao que, porém, possibilita que o diverso do fenômeno possa ser ordenado segundo determinadas relações, dou o nome de $<<$ forma $>$ do fenômeno."(KANT, 1985, p.62)

Onde a matéria nos é fornecida como dado a posteriori mediante a experiência, e a forma como aspecto que se encontra no espírito a priori, independente de toda e qualquer experiência. Esta última, pronta para estabelecer ordem sobre a matéria.

Assim, a sensibilidade constituir-se-ía como uma síntese imediata entre o objeto visto e a nossa capacidade receptiva, da qual podemos analisar, mediante um ato reflexivo, e encontrar elementos de ordem objetiva e elementos de ordem subjetiva. Dos primeiros observamos os fenômenos em sua matéria, e dos segundos encontramos a forma, o que impede que o mundo se disponha como um "caos de fenômenos". São destes segundos, que Kant designa como "puras" (transcendentais), todas as representações que não se misturam à sensação, sendo, entretanto, o elemento formal da sensação.

"Chamo puras (no sentido transcendental) todas as representações em que nada se encontra que pertença à sensação. Por conseqüência, deverá encontrar-se absolutamente a priori no espírito a forma pura das intuições sensíveis em geral, na qual todo o diverso dos fenômenos se institui em determinadas condições. Essa forma pura da sensibilidade chamar-se-á também intuição pura. Assim, quando separo da representação de um corpo o que o entendimento pensa dele, como seja substância, força, divisibilidade, etc., e igualmente o que pertence à sensação, como seja a impenetrabilidade, dureza, cor, etc., algo me resta ainda dessa intuição empírica: a extensão e a figura. Estas pertencem à intuição pura, que se verifica $a$ priori no espírito, mesmo independentemente de um objeto real dos sentidos ou da sensação, como simples forma de sensibilidade.”(KANT, 1985, p.62) 
Nesta direção caminha Kant, levando-nos a considerar a existência de uma ciência de todos os princípios da sensibilidade a priori, a qual designa como Estética Transcendental, aquilo que consistira na primeira parte da teoria transcendental dos elementos. Da mesma forma que em relação ao pensamento haverá uma Lógica Transcendental.

Na constituição da estética transcendental, Kant faz por destacar a sensibilidade, abstraindo todos os elementos do entendimento, para que se registre apenas a intuição empírica. Da intuição empírica busca separar os aspectos referentes à sensação, de modo que só reste em consideração à intuição pura, a forma dos fenômenos, a única medida a priori que a sensibilidade pode dar.

\footnotetext{
“Nesta investigação se apurará que há duas formas puras da intuição sensível, como princípios do conhecimento a priori, a saber, o espaço e o tempo, de cujo exame vamos nos ocupar." (KANT, 1985, p.63)
}

Esta é a posição que espaço e tempo ocupam dentro da Crítica. Resta-nos explicitar melhor o que significam exatamente para Kant o que são estes dois elementos. As perguntas que poderíamos fazer, são: tratam-se de conceitos, e, portanto, são elementos constitutivos dos objetos? A partir disto, poderíamos tomá-los como determinações, formadoras da essência das coisas em si? Serão aspectos existentes a partir das relações dos objetos entre si?

O filósofo responde estas questões mediante duas exposições: a exposição metafísica e a exposição transcendental. Sendo que pela exposição metafísica temos o esclarecimento quanto à representação daquilo que é constitutivo de um conceito, onde este aspecto constitutivo posta-se como um dado a priori. Por exposição transcendental, considera-se a explicitação do conceito quando considerado como princípio, que, mediante este, se pode entender a ocorrência de outros conhecimentos sintéticos a priori.

Frente a isto, obtém-se as seguintes respostas: a) que espaço e tempo não são conceitos empíricos derivados da experiência, sendo, entretanto, necessários para que a experiência interior e exterior ${ }^{3}$ sejam possíveis; b) tratam-se de representações necessárias a priori, sendo que o espaço fundamenta todas as intuições externas e o tempo como fundamento constitutivo de todas as intuições. Para o filósofo nunca podemos ter uma representação em que não haja espaço e tempo, embora possamos pensá-los sem objeto algum; c) não são, nem o espaço e nem o tempo, conceitos discursivos, mas, sim, intuições puras. Pois, só podemos ter a representação de um único espaço e quando nos referimos a vários espaços, estamos na verdade nos referindo a partes de um só e mesmo espaço.

\footnotetext{
${ }^{3}$ Entende-se, aqui, por "interior" aquilo que remete aos sentidos internos do pensamento e "exterior" aos sentidos externos do sujeito.
} 
"Estas partes não podem anteceder esse espaço único, que tudo abrange, como se fossem seus elementos constituintes (que permitissem sua composição); pelo contrário, só podem ser pensados nele. É essencialmente uno; a diversidade que nele se encontra e, por conseguinte, também o conceito universal de espaço em geral, assenta, em última análise, em limitações. De onde se conclui que, em relação ao espaço, o fundamento de todos os seus conceitos é uma intuição a priori (que não é empírica).” (KANT, 1985, p.65)

Consideramos esta passagem, acima grifada, como sendo um dado essencial para nossas futuras conclusões. Portanto, decorrente disto, é que, dentro desta exposição sumária do pensamento de Kant, achamos necessário acrescentar as últimas observações feitas dentro da exposição metafísica do espaço, ao que se segue:

\begin{abstract}
"O espaço é representado como uma grandeza infinita dada. Ora, não há dúvida que pensamos necessariamente qualquer conceito como uma representação contida numa multidão infinita de representações diferentes possíveis (como sua característica comum), por conseguinte, subsumindo-as; porém, nenhum conceito, enquanto tal, pode ser pensado como se encerasse em si uma infinitude de representações. Todavia é assim que o espaço é pensado (pois todas as partes do espaço existem simultaneamente no espaço infinito). Portanto, a representação originária de espaço é intuição a priori e não conceito.” (KANT, 1985, p.65-6)
\end{abstract}

Em relação ao tempo, estas últimas considerações se aplicam com pequenas especificidades. Ou seja, de qualquer grandeza de tempo determinada que tenhamos, esta só é possível mediante a existência de um tempo único e infinito. Portanto, contitui-se como sendo, também o tempo, uma intuição a priori.

Em resumo, as considerações de Romano Galeffi nos parecem esclarecedoras das funções do espaço e do tempo no pensamento de Kant:

\begin{abstract}
"Em substância, espaço e tempo são as fontes que organizam toda a experiência sensível e delas podem ser hauridos, a priori, vários conhecimentos sintéticos, como é demonstrado, de maneira particular, pela matemática pura, no que concerne ao conhecimento do espaço e suas relações. Mas estas duas fonte a priori do conhecimento são a priori simples condições da sensibilidade e não determinações reais dos objetos, os quais nos são, alias, desconhecidos em sua realidade em si, e só são conhecidos em sua fenomenicidade.”(GALEFFI, 1986, p.70)
\end{abstract}

Desta forma temos, então, que o espaço é uma função da sensibilidade que permite pôr forma (ou ordem) aos sentidos externos; do tempo, temos a propriedade de estabelecer a forma (a ordem) dos sentidos internos do sujeito. Da matéria que repercute nos nossos sentidos pela via de sua fenomenicidade, ganha ordenamento, livrando-se do caos. Este no qual sem a presença apriorística do espaço e do tempo estaria sujeita a nossa sensibilidade.

Dentro do que já foi por nós exposto aqui, poderíamos nos deter quanto à contextualização da questão do espaço e do tempo dentro da Crítica. Ocorre que 
seria um desperdício de esforço não levar esta exposição um pouco mais adiante, haja visto termos elementos importantes ao que aqui nos interessa.

Portanto, recapitulemos brevemente.

Foi mencionado anteriormente que os dois principais ramos do conhecimento humano são a sensibilidade e o entendimento. À sensibilidade, como se viu, cabem os elementos atinentes à intuição, postos na Crítica como constituintes da ciência das leis da sensibilidade em geral, a estética transcendental. Daqui se considera sobre a receptividade do espírito às representações do mundo que o percepciona.

Já do entendimento, teremos que falar de quando o pensamento produz as representações, ou seja, o entendimento constrói representações na medida que se debruça (passa a pensar) sobre os elementos tidos na sensibilidade, na intuição. Se na sensibilidade tínhamos a estética, para o entendimento teremos as leis do entendimento em geral ou Lógica.

Kant, a este respeito, divide a lógica em dois diferentes tipos: uma denomina-se geral, concernente aos procedimentos do entendimento em geral; a outra denominase especial, pois refere-se às maneiras corretas de pensar um tipo específico de objeto, representando com isto a postura lógica específica de uma determinada ciência. Da lógica geral recorre ser esta a mais importante, uma vez que a especial tem esta por base. A lógica geral representa os procedimentos mais íntimos da razão, donde temos ser ela pura ou aplicada.

Pura, quando

"abstraímos de todas as condições empíricas relativamente às quais se exerce nosso entendimento, por exemplo, a influência dos sentidos, do jogo da imaginação, das leis da memória, do poder do hábito, da inclinação, etc., portanto também as fontes dos preconceitos e, em geral, de todas a causas de onde podem derivar ou se supõe provirem determinados conhecimentos e, porque essas causas dizem respeito ao entendimento apenas em determinadas circunstâncias da sua aplicação, para as conhecer exige-se a experiência. Uma lógica geral, mas pura, ocupase pois, de princípios puros a priori e é um cânone do entendimento e da razão, mas só com referência ao que há de formal no seu uso, seja qual for o conteúdo (empírico ou transcendental)."(KANT, 1985, p.90)

Aplicada, quando trata não só das leis do pensamento por ela considerada, como também procede na função transcendental de ordenar a experiência. Ou seja,

"quando se ocupa das regras do uso do entendimento nas condições empíricas subjetivas que a psicologia nos ensina. Tem, pois, princípios empíricos,embora seja, na verdade, geral na medida em que se ocupa do uso do entendimento sem distinção dos objetos. Por esse motivo não é um cânone do entendimento em geral, nem um organon de ciências particulares, mas simplesmente um catarticon do entendimento comum."(KANT, 1985, p.90)

Em síntese temos, pois, que a lógica geral pura (ou, simplesmente, lógica formal), refere-se àqueles procedimentos do pensamento onde nada da experiência é 
considerado, nada que diz respeito ao objeto é relevado. Busca-se muito mais uma coerência do pensamento consigo mesmo, na perspectiva de estabelecer regras de retidão e coerências formais de pensamento, abstraindo todo o conteúdo do pensamento. Esta seria propriamente a lógica de Aristóteles.

Mas, para Kant existiria ainda uma outra lógica. Uma lógica que não desconsideraria o conteúdo do conhecimento, mas que possuiria a priori elementos que garantissem a retidão das experiências empíricas do sujeito, e por isso lhe permitiria assegurar as conclusões verdadeiras necessárias. Seria, a bem dizer, a admissão de que, mediante o fato da existência de formas a priori do entendimento, admite-se também um modo de pensar os objetos independente da experiência, determinando, entretanto, esta experiência. A esta lógica, denominou de lógica transcendental. Aquilo que passou para a história da filosofia sendo uma "revolução coperniquiana", operada por Kant.

A lógica transcendental possui duas seções: a primeira denominada analítica transcendental, preocupa-se em exibir os elementos do conhecimento puro do intelecto e os princípios sem os quais nenhum objeto pode absolutamente ser pensado. Trata-se da lógica da verdade, onde nenhum conhecimento pode se opor sem perder toda a relação com o conteúdo e, por conseguinte, toda a verdade.

A segunda seção refere-se à dialética transcendental. Aqui verifica-se os riscos que corre o conhecimento estabelecido através de princípios puros, em se perder em sofismas e, mediante isto, emitir juízos que em nada se referem ao objeto. Como é presente verificar, a designação dialética foge à costumeira interpretação que temos deste vocábulo. Trata-se na verdade da concepção originária atribuída a ela na lógica de Aristóteles, onde o sentido é posto como a tudo aquilo que se refere aos juízos que são desprovidos de valor objetivo.

Referente à analítica transcendental, Kant preocupa-se em expor logo de início suas principais características:

"Esta analítica é a decomposição de todo o nosso conhecimento a priori nos elementos do conhecimento puro do entendimento. Deverá nela atender-se ao seguinte: 1. Que os conceitos sejam puros e não empíricos. 2. Que não pertençam à intuição nem a sensibilidade, mas ao pensamento e ao entendimento. 3. Que sejam conceitos elementares e sejam bem distintos dos derivados ou dos compostos de conceitos elementares. 4. Que a sua tábua seja completa e abranjam totalmente o campo do entendimento puro. Ora, esta integral perfeição de uma ciência não pode ser aceita com confiança se assentar apenas sobre o cálculo aproximativo de um agregado, obtido por simples tentativas; daí que seja somente possível mediante uma idéia da totalidade do conhecimento a priori do entendimento e pela divisão, determinada a partir dessa idéia, dos conceitos que o constituem, por conseguinte pela sua interconexão num sistema. $\mathrm{O}$ entendimento puro distingue-se totalmente não só de todo o elemento empírico, mas também de toda sensibilidade. É, pois, uma unidade subsistente por si mesma e em si mesma suficiente, que nenhum acréscimo do exterior pode aumentar. Daí que o conjunto do seu conhecimento constitua um sistema, a abranger e determinar por uma idéia, sistema cuja perfei- 
ção e articulação possa oferecer, ao mesmo tempo uma pedra de toque da exatidão e genuinidade de todos os conhecimentos que nela se incluam."(KANT, 1985, p.97)

Partindo destas premissas o filósofo, exercerá a tarefa nada simples de identificar quais são exatamente os conceitos que são caracterizados como puros. Estes que permitirão ao pensamento dar forma ao que na sensibilidade já foi espacializado e temporalizado.

E aqui se verifica que Kant recorre ao auxílio da lógica clássica como ponto de apoio para identificar quais os conceitos que merecerão a designação de serem puros. Ou seja, sua tábua de categorias foi tomada de empréstimo de Aristóteles, sendo, entretanto, estabelecidas significativas alterações. Portanto, segundo Kant, a disposição dos juízos obedeceria a seguinte classificação:

a) segundo a quantidade, verificando-se aqui a determinação quantitativa do sujeito em relação ao predicado, onde os juízos podem ser singulares, particulares e universais, correspondendo no sistema transcendental às categorias de totalidade, unidade e pluralidade;

b) segundo a qualidade, admitindo-se a designação dos juízos como sendo afirmativos, negativos e indefinidos, onde o predicado em relação ao sujeito pode assumir estas três posturas. Aqui as categorias correspondentes.são: a negação, a realidade e a limitação;

c) dispostos segundo a relação, onde o predicado em um juízo pode ser afirmado incondicionalmente, portanto teremos um juízo categórico; ou, então, postase condicionalmente, e aí teremos um juízo hipotético; e, finalmente, teremos a condição de alternatividade, estabelecendo um juízo disjuntivo. Temos aqui as categorias de substância-acidente, causa-efeito e ação recíproca;

d) segundo a modalidade onde o predicado firma-se junto ao sujeito de forma problemática, assertória ou apodítica. Correspondem aqui as categorias de possibilidade-impossibilidade, existência-inexistência e necessidade-contingência.

Não poderíamos, antes de encerrarmos esta exposição sumária da Crítica, considerarmos sob que autoridade o filósofo atribui o caráter transcendental a estas categorias. Primeiramente, se faz mister lembrarmos que o que está em curso é o observar de fenômenos. Pois, a essencialidade do que é observado, o em-si propriamente das coisas, aos olhos do filósofo, é uma meta inatingível. Dado este impedimento, seria impossível imaginar que as categorias derivassem da análise da essência do objeto. O que se verifica, portanto, é o oposto. Ou seja, são os fenômenos que serão assegurados em sua objetividade por estas categorias de natureza apriorística. Fica, com isto, assegurado o conhecimento científico, mediante este caráter objetivante dado por estas categorias, ou seja os fenômenos podem ser agora cientificamente pensáveis. Mas, ainda assim permanece a dúvida; que garantias temos que as categorias apresentadas fazem parte do patrimônio apriorístico do intelecto e, portanto, são a medida da universalidade? A natureza desta resposta é semelhante às justificativas 
da existência de elementos apriorísticos contidos na sensibilidade, sendo, entretanto, agora designada em relação ao entendimento:

"O diverso das representações pode ser dado numa intuição simplesmente sensível, isto é, que não seja mais do que receptividade, e a forma desta intuição pode encontrar-se a priori na nossa capacidade de representação, sem que seja algo diferente da maneira que o sujeito é afectado. Simplesmente, a ligação de um diverso em geral não pode nunca advir-nos dos sentidos e, por consequência, também não pode estar, simultaneamente, contida na forma pura da intuição sensível, porque é um ato de espontaneidade da faculdade de representação; e já que temos de dar a esta última o nome de entendimento, para distinguir da sensibilidade, toda a ligação, acompanhada ou não de consciência, quer seja ligação do diverso da intuição ou vários conceitos, quer, no primeiro caso, seja uma intuição sensível ou não sensível, é um ato do entendimento a que aplicaremos o nome genérico de síntese para fazer notar, ao mesmo tempo, que não podemos representar coisa alguma como sendo ligada no objeto se não a tivermos nós ligado previamente e também toda as representações, a ligação é a única que não pode ser dada pelos objetos, mas realizada unicamente pelo próprio sujeito, porque é ato da sua espontaneidade.(...)

A representação dessa unidade não pode, pois, surgir da ligação, foi antes juntando-se à representação do diverso que possibilitou o conceito de ligação. Esta unidade, que precede $a$ priori todos os conceitos de ligação, não é a categoria da unidade; porque todas as categorias têm por fundamento as funções lógicas nos juízos e nestes é pensada a ligação, por conseguinte a unidade de todos os conceitos dados. A categoria pressupõe, portanto, já a ligação. Temos, pois, que buscar esta unidade (como qualitativa) mais alto ainda, a saber, no que já propriamente contém o fundamento da unidade de conceitos diversos nos juízos e, por conseguinte, da possibilidade do entendimento, mesmo no seu uso lógico."(KANT, 1985, p.129-31)

Se unimos dois objetos pela relação de causa e efeito, também o podemos fazer, ao mesmo tempo, enquanto representações mentais. Mas, se estas duas coincidentes unificações são possíveis, o são graças à terceira e precedente síntese, a qual nos permite realizar estas respectivas ligações. Algo superior à subjetividade empírica $\mathrm{e}$ à objetividade empírica. Uma espécie de propriedade de unificação pura, a priori, presente no entendimento e precedente às experiências.

A imperiosa certeza do entendimento em sua verdade é assegurada pelas categorias a priori contidas no intelecto, estabelecida pela unidade sintética da consciência, o que permite estabelecer a segurança nos procedimentos sintéticos e analíticos.

Concluímos assim o que a nós interessava extrair da Crítica. Vimos, portanto, a lista de categorias da lógica transcendental de Kant. Nosso interesse em chegar até aqui, na exposição desta obra, está em verificar a natureza do sistema lógico kantiano. De outro lado, levamos as considerações até aqui para destacar o fato de que, no processo de elaboração da verdade pelo entendimento, espaço e tempo estão fora da mencionada tábua das categorias. Estabeleceu-se uma distinção marcante em relação a Aristóteles. Na verdade, como vimos, de categorias em Aristóteles, espaço e 
tempo em Kant, tornaram-se atributos a priori da sensibilidade em suas representações empíricas. Deixam de possuir a característica de constituírem modos de existência do ser. As implicações disto estão nos desdobramentos que Kant fará da Crítica.

É o caso, por exemplo, verificado no seu trabalho Princípios Metafísicos da Ciência da Natureza. Trabalho realizado em 1785, quando o autor estava envolvido com a segunda edição da Crítica. O propósito desta obra, segundo Artur Morão, tradutor da versão portuguesa do trabalho em questão, era ser um complemento à Crítica. Morão, citando Robert E. Butts, no trabalho intitulado Philosophy of Science, Metaphysische Anfangsgründe der Naturwissenschaft 1786-1986, afirma que Kant neste trabalho põe a serviço da ciência da natureza todas as categorias desenvolvidas na Crítica, como verificamos nesta passagem da nota do tradutor:

\footnotetext{
"Por outro lado, a ciência natural tem como objeto a matéria; e o programa de Kant leva-o a estruturar este conceito de acordo com quatro grupos categoriais, enquanto exemplificadas pelo movimento. Daí a subdivisão teórica dos objetos físicos em: foronomia(cinemática), isto é, a geometria pura do movimento enquanto apenas pontos composicionais (categoria da quantidade)-grifo nosso-; dinâmica que estuda o movimento como qualidade da matéria e explica as mudanças qualitativas mediante a força motriz originária (âmbito da categoria de qualidade); mecânica que investiga as relações externas entre os objetos físicos que-se movem dinamicamente (categoria da relação) e fenomenologia que se ocupa com movimento ou repouso da matéria nas suas manifestações perante os sentidos externos (categoria da modalidade)."(MOURÃO, 1990, p.11)
}

Vale como registro lembrar que a influência da conjuntura científica, na qual Kant estava inserido, era já a da existência da mecânica newtoniana. O filósofo não escapa a esta influência, pois é carregado pela crise da metafísica em relação ao desenvolvimento da física e da matemática, bem como os elementos paradigmáticos que se construíam como relação ao caráter científico do conhecimento. Este último aspecto derivado da "filosofia experimental", esta que exercia um apelo considerável no que diz respeito aos procedimentos científicos.

Portanto, a obra de Kant, especialmente os textos de sua fase assim chamada, crítica, representa o resultado desta inquietação em trazer este modelo de cientificidade para dentro da metafísica. Já a obra que agora nos ocupamos em analisar trata-se de um exercício dos elementos desenvolvidos na Crítica, tendo como material a física de Newton. De outro lado, o próprio trabalho de Newton receberá o exame e anuência transcendental da Crítica nos Princípios Metafísicos da Ciência da Natureza.

Assim, no capítulo inicial desta obra, dedicado aos Primeiros Princípios Metafísicos da Foronomia, Kant passa a considerar, em uma série de cinco definições, sobre o movimento da matéria no espaço. Temos, portanto, a primeira definição: 
"A matéria é o que é móvel no espaço. O espaço, que é também móvel, chama-se espaço material, ou ainda o espaço relativo; aquele em que, por fim, se deve pensar todo o movimento (por conseguinte, ele é em si absolutamente imóvel) chama-se o espaço puro ou também absoluto."(KANT, 1990, p.25)

Observa-se aqui a relação entre os dados da experiência empírica e seu fundamento apriorístico. Pois, Kant nos fala da impropriedade de definir o conceito de matéria mediante um predicado que lhe caberia como objeto. Sendo assim, só posso tê-lo mediante a relação com a faculdade de conhecer em que a representação pode ser primeiramente dada e, portanto, passo a designar a matéria como sendo todo $o$ objeto dos sentidos externos. Temos aí uma definição de ordem metafísica. Ao que acrescenta:

\begin{abstract}
"Mas o espaço seria apenas a forma de toda a intuição sensível externa (não se trata aqui de saber se esta convém em si ao objeto exterior que chamamos de matéria, ou se reside unicamente na constituição do nosso sentido). A matéria seria, em oposição à forma, o que é, na intuição exterior, um objeto da sensação, por conseguinte, o especificamente empírico da intuição sensível e externa, porque não pode ser dado a priori. Em toda a experiência, algo deve ser sentido e isso é o que há de real na intuição sensível; portanto, também o espaço, em que devemos estabelecer a experiência dos movimentos, deve ser susceptível de sensação, isto é ser designado pelo que pode sentir-se; e este, enquanto complexo de todos os objetos da experiência e ele próprio um objeto da mesma, chama-se espaço empírico. Mas, enquanto material, também é móvel. Um espaço móvel, porém, se é que seu movimento se deve percepcionar, supõe, por seu turno, um outro espaço material alargado, em que ele é móvel, este (supõe) um outro, e assim por diante até o infinito." (KANT, 1990, p.26)
\end{abstract}

Observe-se aqui como Kant transita entre a necessidade de afirmar a realidade empírica dos fenômenos e sua possibilidade de serem percepcionados pelos sentidos. Diante das últimas duas citações, podemos verificar estas transições: da mesma forma que na introdução à Estética Transcendental, a matéria refere-se aos objetos da sensação, aquilo que é dado aos sentidos como externo. Entretanto, agora verificamos a existência de um espaço, que também pode ser considerado empiricamente como constitutivo da realidade externa. Nele será verificado o movimento. Este primeiro espaço passa literalmente a ser objeto da experiência, dotado mesmo de materialidade. Desta última prerrogativa, ou seja de sua materialidade, Kant lhe atribui também, um movimento, um movimento do espaço. Ao que supõe a existência de um espaço "alargado", onde o movimento do primeiro espaço se daria. Mas, este segundo espaço "alargado" deve supor um terceiro maior ainda, contendo o movimento do segundo, e assim até o infinito. Portanto, sempre temos um espaço maior que contém o movimento de um espaço menor. Um espaço relativo (em seu movimento) a um outro, até o infinito, até suposição de um espaço absoluto. 
"Admitir um espaço absoluto, isto é, um espaço que, por não ser material, também não pode ser um objeto da experiência, como dado em si significa (admitir) algo que nem em si, nem suas consequências (o movimento no espaço absoluto) se pode percepcionar, em vista da possibilidade da experiência, a qual, no entanto, deve ser sempre estabelecida sem ele. O espaço absoluto nada é, pois, em si, não é um objeto (Objekt), mas significa somente todo o espaço relativo, que para mim sempre posso pensar além do espaço dado e que eu faço retroceder até o infinito para lá de todo o espaço dado, como um espaço que a este encerra e no qual posso admitir o primeiro como móvel. Porque apenas possuo em pensàmento o espaço alargado, embora ainda sempre material, e nada da matéria que o caracteriza me é conhecido, abstraído desta última, e ele é, pois, representado como um espaço puro, não empírico, e absoluto, com o qual posso comparar todo o espaço empírico e representá-lo como nele se movendo, o qual se considera, por conseguinte, sempre imóvel.” (KANT, 1990, p.26-7)

Por conclusão, então, temos que o espaço absoluto é a condição a priori necessária para que possamos verificar pela experiência (e, portanto, a posteriori) o espaço relativo.

Estas circunstâncias se repetem quando Kant anuncia um axioma derivado da quarta definição:

\section{"Definição 4}

Construir o conceito de um movimento composto é representar a priori na intuição um movimento enquanto ele resulta da reunião num móvel de dois ou mais movimentos dados.

\section{Axioma}

Todo o movimento, enquanto objeto de uma experiência possível, pode a bel-prazer considerar-se como movimento de um corpo num espaço em repouso ou então, enquanto repouso do corpo, como o movimento do espaço em sentido oposto e com uma capacidade igual."(KANT, 1990 , p.32-3)

Kant considera que para fazermos a experiência do movimento de um corpo, deve-se assegurar a existência do próprio corpo bem como do espaço como objetos da experiência externa. De outro lado, tomando o movimento absoluto em relação ao espaço não material (um dado a priori), o primeiro não pode ser um objeto derivado da experiência. Entretanto, tomando em consideração o movimento relativo, temos de novo a possibilidade de considerar o espaço como dotado de materialidade. Diante disto considera:

"O primeiro caso ocorre quando para além do espaço, em relação ao qual vejo um corpo em movimento, nenhum outro espaço mais amplo é dado e que o englobe (como quando na cabina de um barco eu diviso um globo que se move em cima da mesa); o segundo ocorre, quando para além deste espaço me é dado ainda um outro espaço que o engloba (como, no exemplo aduzido, a margem do rio), porque então, em relação a este último espaço, posso olhar o espaço próximo (a cabina) como em movimento e o próprio corpo, em rigor, como imóvel.” (KANT, 1990, p.33) 
Donde Kant considera absolutamente impossível decidir se um espaço empírico, por maior que seja, está ou não em movimento em relação a um espaço maior que o englobe. Ou então, uma vez que o espaço absoluto é indiferente a toda a experiência possível, teremos conceitos equivalentes se eu considerar um corpo em movimento com uma velocidade dada, ou então desejarmos lhe atribuir repouso e darmos ao espaço a mesma velocidade, mas em direção oposta.

Em termos conclusivos, em relação à foronomia, onde é considerado o movimento do corpo em relação ao espaço, Kant afirma ser totalmente indeterminado ou mesmo arbitrário precisar se devemos atribuir ao corpo, ou ao espaço, o movimento

Não é necessário que nos alonguemos, para considerar acerca das concepções kantianas sobre o espaço, nesta obra Princípio Metafísicos da Ciência da Natureza. O que já é lícito afirmar, é o fato de termos uma relação entre experiência e entendimento estabelecida mediante a suposição de um espaço empírico, dotado de materialidade, que é tomado como relativo. De outro lado, referente às prerrogativas sensíveis do entendimento, temos um espaço imaterial, infinito, e, portanto, absoluto. $\mathrm{O}$ primeiro trata-se de um elemento a posteriori revelado a nós pela experiência, sendo, entretanto, possível tê-lo uma vez que possuímos aprioristicamente, independente da experiência, um espaço como forma das intuições puras.

Cumpre destacar que este último espaço, este que nos é dado aprioristicamente, verifica-se como estando por englobar os diversos espaços relativos.-Da mesma forma que um "relativo" maior engloba um "relativo" menor, mas sendo todos relativos a um absoluto, que é essencialmente uno. Conclusão, esta, que já era possível verificar nas passagens da $\mathrm{Crítica}^{4}$ acerca do espaço. Ou seja, mediante o espaço absoluto, podemos nele pensar os espaços relativos, e, por conseguinte, não devemos tomálos como partes constitutivas do espaço absoluto. Algo semelhante também encontrávamos no texto Acerca do Primeiro Fundamento da Diferença das Regiões do Espaço.

Para completar nossa exposição do pensamento de Kant referente ao papel do espaço em sua obra, observamos agora aquilo que foi considerado a herança por excelência deixada por este filósofo para a ciência geográfica. Trata-se da aula introdutória que Kant desenvolvia em suas preleções sobre geografia física. O texto que vamos usar deriva de uma tradução livre das obras completas do autor (em língua alemã) e tem a designação Kant's Gelammelt Schriften.

Logo no início encontramos a seguinte observação:

\begin{abstract}
"Em nossos conhecimentos temos que, primeiramente, dirigirmos a atenção sobre as fontes ou a origem destes, mas também sobre o plano de sua desordem ou sobre a forma em que este conhecimento pode ser ordenado; o que na não observância deste aspecto, não estaremos em condições, em situações subseqüentes, quando da sua necessidade, de recorrer a eles."
\end{abstract}

\footnotetext{
${ }_{5}^{4}$ Ver citação da página 50.

'Dado o caráter da tradução aqui consultada, as citaçōes não constarão de referência quanto à página e ano da edição.
} 
Diante disto, Kant estabelece as fontes do nosso conhecimento: como visto em passagens anteriores, eles derivam, ou da razão como elementos puros, ou da experiência que nos é permitida pelos sentidos. Temos, ainda, um duplo sentido, um externo e um interno, mediante os quais nos é dada, respectivamente, de um lado a Natureza e de outro a alma ou o Homem. Conjuntamente estes conhecimentos constituem o conhecimento que temos do mundo. Sobre o Homem nos ensina a antropologia e sobre a natureza nos é dado saber pela geografia física.

\begin{abstract}
“A descrição física da terra é então a primeira parte do conhecimento do mundo. Ela faz parte de uma idéia, a qual se pode chamar de preliminar ou introdutória no conhecimento do mundo.

(...)

Nós antecipamos nossa futura experiência, a qual teremos posteriormente no mundo, por um esboço geral desse tipo, o qual nos dá como uma prenoção de tudo. Daquele, que fez muitas viagens, fala-se, que ele vive o mundo. Mas para o conhecimento do mundo é preciso mais do que apenas vê-lo. Quem quer tirar proveito de sua viagem, precisa, já antecipadamente, traçar um plano de sua viagem, mas não considerar o mundo apenas como objeto do sentido externo. (...)"
\end{abstract}

Mediante isto, Kant desenvolve a preocupação de que é necessário que tenhamos uma perspectiva da totalidade do mundo, desenvolvida através de conhecimento que adquira uma forma sistêmica distiguindo-se de um mero agregado. Pois crê que no sistema, o todo está entre as partes, o que seria diferente de tomar as partes como simplesmente existindo sem reportar-se a uma totalidade.

Esta condição deve ser dada a todas as ciências, que nos permitirão verificar o todo em concatenação, estabelecida pelo conhecimento produtor desta concatenação. Para este conhecimento, o filósofo usa o exemplo da enciclopédia. Mas, vai mais longe:

\footnotetext{
"A idéia é arquitetônica, ela cria as ciências. Quem, por exemplo, quer construir uma casa, tem primeiro uma idéia do todo, da qual depois as partes derivarão. Assim, então, a nossa presente preparação é também uma idéia do conhecimento do mundo. A saber, fazemos aqui igualmente uma idéia arquitetônica, a qual é uma noção, donde o diverso é deduzido do todo."
}

$\mathrm{Na}$ sequência de sua exposição introdutória, Kant nos fala mais uma vez das fontes do conhecimento: a experiência e a razão. Alimenta a necessidade de ampliarmos o possível nossa experiência, reconhecendo sua importância no conhecimento da natureza e do Homem. Entretanto, admite a limitação existente na extensão das experiências possíveis na vida de um único indivíduo. Trata-se da existência de uma vida somente, o que é ínfimo em termos de tempo para que este indivíduo possa assomar um número considerável de conhecimentos derivados da experiência. Para tanto, admite a necessidade de apelarmos para relatos, narrativas ou descrições, tanto de épocas pregressas como atuais. 
"Mas, tome-se nota disto: toda a experiência desconhecida é comunicada a nós, ou por narrativa (conto), ou por descrição. A primeira é uma história, a outra uma geografia. A descrição de um só lugar da terra chama-se topografia. Corografia, significa a descrição de uma região e suas particularidades. Orografia, descrição destas ou daquelas montanhas. Hidrografia, descrição das águas."

Diante disto configura-se a necessidade de estabelecer um ordenamento, ou uma classificação, dos conhecimentos empíricos. Podemos fazê-lo, segundo Kant, adotando dois procedimentos: ou mediante uma classificação a partir dos conceitos, e aí teremos um sistema lógico, ou então de acordo com o espaço ou o tempo, e aí teremos uma divisão física.

Se adotarmos o ordenamento partindo-se do conceito, obteremos um sistema natural (Systema Naturae). No segundo caso o nosso resultado será uma descrição de natureza geográfica. No sistema natural obtemos a possibilidade, por exemplo, de classificar o gado bovino no gênero dos animais quadrupedes, ou então entre aqueles de cascos fendidos. Esta forma de classificar, adverte o filósofo, é feita em nosso pensamento, o que decorre ser uma classificação lógica.

"O Systema Naturae é como que um registro do todo, onde eu coloco todas as coisas, cada uma em sua classe característica, podendo elas encontrarem-se sobre a Terra em diversas regiões, distantes uma das outras."

Da classificação física, entretanto, consideramos as coisas segundo os seus respectivos lugares ocupados sobre a Terra. E Kant nos dá o exemplo do crocodilo e do lagarto, que considerava basicamente o mesmo animal, variando somente no tamanho. Porém, o crocodilo se encontra no Nilo, e o lagarto na terra, separados por enorme distância.

"Em geral consideramos aqui o cenário da natureza, a própria terra e as regiões, onde as coisas realmente serão encontradas."

Para o sistema natural, em termos conclusivos, Kant afirma que se trata de um procedimento que já coloca antecipadamente uma idéia do todo, onde é deduzida a variedade das coisas. Para a História e a Geografia, o filósofo tem o seguinte a dizer:

"Nós podemos chamar ambos, História e Geografia, também de uma descrição uniforme, mas com uma diferença, que a primeira é uma descrição dos fenômenos no tempo, a segunda uma descrição segundo o espaço.

Portanto, a História e a Geografia alargam os nossos conhecimentos em relação ao tempo e ao espaço. A História atinge os acontecimentos, os quais, em consideração do tempo, se sucederam um atrás do outro. A Geografia aborda fenômenos, os quais, em consideração ao espaço, aconteceram ao mesmo tempo. Conforme os diferentes objetos, com os quais a última se ocu- 
pa, ela recebe diversos nomes. Em consequêencia disso, ela se chama logo geografia física, matemática, política, moral, teológica, literária ou mercantil."

Acrescenta a isto a afirmação de que a história, acontecida em tempos diferentes, não é outra coisa que a contínua geografia. E, portanto, salienta a necessidade de sempre sabermos o lugar onde os episódios aconteceram. Insiste em afirmar que a História é como se fosse uma notícia dos acontecimentos que sucederam um sobre o outro em relação ao tempo, enquanto a Geografia são notícias dos acontecimentos que passam um ao lado do outro no espaço. Enfim, a História estabelece uma narrativa e a Geografia uma descrição.

Decorrente disto, é dito que podemos ter uma descrição da natureza, mas nunca uma história natural, ou seja, uma vez que isto é o registro dos acontecimentos em todos os tempos, para o caso da natureza nos encontraríamos impossibilitados de fazê-la tendo em vista a falta de dados mais completos.

Na continuação de sua preleção, Kant pergunta: o que vem antes a Geografia ou a História? A isto responde da seguinte forma:

\footnotetext{
"Mas o que estava antes aí, História ou Geografia? A última está no fundamento da primeira, pois os acontecimentos precisam se ligar a algo. A História está em um contínuo progresso, mas as coisas também se transformam e dão em certos tempos em outra Geografia. A Geografia é, portanto, o substrato. Temos, então, uma História antiga, e assim precisamos naturalmente de uma Geografia antiga."
}

Assim, é necessário para a expansão da experiência a presença do conhecimento da Geografia. Na ausência disto não estaríamos em condições de reconhecer acontecimentos que se dão em determinado lugar. Estaríamos desprovidos de uma visão mais geral sobre a Terra, guardando com isto uma atitude indiferente sobre algum acontecimento em lugar recôndito deste planeta. Vejamos como Kant ilustra isto:

\footnotetext{
"Há dificilmente uma nação, na qual o entendimento se estendeu de forma tão massiva a todas as camadas da população, como é o caso dos ingleses. Causa disto são os jornais, cuja leitura pressupõe uma extensa noção de toda a superfície da Terra. Em não sendo assim, todas as notícias ali encontradas nos são indiferentes, enquanto dela não soubermos fazer uso. Os peruanos são de índole ingênua, uma vez que tudo o que lhes é oferecido colocam na boca, porque eles não estão em condições de compreender como poderiam fazer uso conveniente disso. Essas pessoas, as quais não sabem utilizar as noticias de jornal, não o fazem porque não tem nenhum lugar para elas. Encontram-se como esses pobres peruanos."
}

Estão estabelecidas a importância e a finalidade da ciência geográfica. Mas as descrições só serão completas se observarem os diversos aspectos constituintes das diferentes realidades. Diante disto, além da geografia física, que trata de um esboçó geral da natureza, é necessário que, tomando esta última como substrato, considere- 
se sobre as distintas partes que compõe a geografia. Assim, temos a geografia matemática, tratando da forma, movimentos e tamanho da Terra, bem como sua posição no sistema solar; uma geografia moral relatando os diferentes costumes e características do homem; uma geografia política, estabelecendo um estudo entre as unidades políticas e sua base física; uma geografia comercial, reportando-se à razão do por que determinados países possuem excesso de uma específica mercadoria, enquanto outros possuem deficiência; e, finalmente, uma geografia teológica, estudando as alterações sofridas pelos ditames teológicos segundo diferentes meios.

Aqui está, então, em síntese a exposição inicial de Kant de suas aulas de geografia física. É tida como sendo a herança que configura o impasse aristotélico-kantiano, que estamos aqui longamente analisando. Mas, é difícil crer que a ciência geográfica herdou de Kant somente aquilo que foi exposto em sua preleção inicial. Admitimos mesmo, que dada a importância deste filósofo no contexto do desenvolvimento da ciência em geral, que sua marca sobre o pensamento geográfico tenha se estabelecido para além desta direta indicação quanto ao papel da geografia na construção do conhecimento. É necessário, portanto, que concluamos em síntese o que foi anteriormente considerado.

No transcurso de nossa exposição, procuramos pontuar os diversos momentos onde a questão (especialmente) do espaço esteve presente na obra deste pensador. A partir disto, consideramos o seguinte: a) da mesma forma que Aristóteles, Kant estabeleceu relação entre o espaço e a categoria de quantidade. Vemos esta associação, mais claramente estabelecida, nos Princípios Metafísicos da Ciência da Natureza, onde temos a discussão acerca da natureza do espaço no capítulo um dedicado aos princípios metafísicos da foronomia ${ }^{6}$; b) a despeito de ter colocado espaço e tempo fora das tábuas das categorias, admitiu a existência de um espaço empírico referente aos objetos da realidade, mesmo que tenhamos que considerá-lo relativo a um espaço absoluto, imaterial, apriorístico, um aspecto constitutivo da intuição pura. Neste espaço empírico-relativo, é que podemos localizar as coisas em suas situações, e, mediante isto, estabelecer as regiões do espaço, sendo, entretanto, necessário que estabeleçamos sempre a relação com o espaço absoluto. O que cabe assomar a esta última conclusão, que temos mais uma vez a idéia de espaço como todo e região como parte.

Mas, quais as conseqüências destas conclusões?

Temos que a associação entre o espaço e a categoria da quantidade esta estabelecida mediante a concepção de movimento, derivada da mecânica newtoniana, a saber o deslocamento. Esta compreensão junta-se ao fato de associar a propriedade de ex-

\footnotetext{
${ }^{6}$ É verdade, também, que encontramos referência ao espaço nos demais capítulos desta obra, especialmente no capítulo 2, denominado Princípios metafísicos da Dinâmica, sendo este associado à categoria de qualidade. Neste capítulo, o aspecto qualitativo em questão é o próprio movimento em relação à matéria, estabelecido por forças de atração, repulsão, força motriz, etc. Entretanto, o que é verificado é o fato de independente da natureza da força considerada, o movimento é concebido sempre como deslocamento, da mesma forma que insiste na idéia de extensão associada à de espaço.
} 
tensão para o espaço. Ou seja, a natureza do movimento verificado - o deslocamento- é coerente à perspectiva quantitativa, o que remete ao entendimento de espaço enquanto extensão geométrica, portanto concebido a partir de uma linguagem. E aqui verifica-se $o$ aspecto formal de Kant, onde este toma a geometria como elemento "formatador" da realidade, sendo esta exatamente a perspectiva de verdade necessária ao conhecimento (a pura forma, que nos é dada aprioristicamente). Equivale dizer que a disposição dos fenômenos no mundo obedece um ordenamento geométrico, da mesma forma que seus movimentos se processam num deslocamento mecânico.

Isto também é verificável em relação ao denominado espaço empírico. Neste caso, é admitido como único passível de variações quantitativas, sendo que este é, nas palavras do próprio Kant, concebido sobre limitações ${ }^{7}$. Ou seja, enquanto elemento contingencial, se estabelece como descontínuo e relativo. Algo oposto no que ocorre como faculdade da intuição pura, mostrando-se necessário, contínuo e absoluto. Este último deriva-se das mesmas concepções dos geômetras e dos físicos, e neste sentido reveste-se da certeza de verdade. O diverso ocorre com o espaço relativo-empírico. Mas, é necessário que se destaque que as diretrizes axiomáticas da geometria são fundamentalmente construções de ordem formal, ou seja, pura forma que se justifica a si em detrimento do conteúdo.

Enfim, os objetos se deslocam no espaço. Mesmo quanto considera supostamente um movimento do espaço, como o que verificamos nos Princípios Metafísicos da Ciência da Natureza, este também é tomado como puro deslocamento. Ou seja, o que marca a concepção kantiana de espaço é sua invariância do ponto de vista qualitativo. E, sob o ponto de vista da quantidade, é Hegel quem observa:

"É que, quando se diz da quantidade que seu conceito consiste em poder ser aumentada ou diminuída, com isso se anuncia justamente que a grandeza (ou, mais exatamente, a quantidade) - diversamente da qualidade - é uma determinação tal que a Coisa determinada se comporta como indiferente para com a variação dela.(...) Ora, também a quantidade é variável, e a diferença anteriormente mencionada entre quantidade e qualidade é então expressa por meio do aumentar ou diminuir, e nisso está implicado que, seja qual for o lado conforme o qual varie a determinação de grandeza, contudo a Coisa permanece o que é.”(Hegel, 1995, p.200)

Isto, a nosso ver, repercute em conseqüências de ordem lógica. Vejamos.

Antes, caberia uma indagação: seria um erro tomar as reflexões sobre o espaço estabelecidas por Kant, quando este se reporta à física ou à geometria, como elementos que seriam pertinentes ao pensamento geográfico? Cremos que não. Isto justifica-se pelo fato de que Kant não apresenta concepções distintas de espaço. Não se trata de uma formulação sobre espaço na Crítica e outro na sua aula introdutória de geografia física. Existe uma linha de coerência estrutural entre o primeiro texto con-

${ }^{7}$ Verificado por nós, neste trabalho, na página 50. 


\section{siderado aqui (Acerca do primeiro fundamento da Diferença das Regiões do Espa-} ço) e a "aula introdutória". O que se estabelece, em verdade, são os patamares gnosiológicos onde o conhecimento se processa. Ou seja, se temos uma concepção de espaço em Kant de natureza empírica, é porque este situa-se no horizonte da experiência sensível externa, na qual o sujeito está submetido, e neste caso, temos um dado a posteriori. $\mathrm{O}$ que permite esta relação sujeito-objeto, levando o observado da sensibilidade ao entendimento, são os elementos apriorísticos da intuição pura, ou seja, o espaço enquanto entidade pura, absoluta, una e indivisível presente a priori no sujeito.

A categoria de quantidade, como vimos, admite juízos de caráter universal, particular e singular. Entretanto, Kant jamais fará considerações lógicas acerca do espaço, uma vez que este foi desconsiderado como categoria. Mas, o fará das coisas situadas no espaço, ou seja, admite mesmo um sistema de classificação da realidade mediante a distribuição espacial. Foi o que vimos em sua preleção inicial sobre a geografia física. Assim, das coisas consideradas na experiência do sujeito, sabe-se que Kant considera um espaço relativo onde tais coisas estão situadas. O universal em relação ao espaço em Kant será sempre o espaço absoluto, não contingencial, necessário e, portanto, apriorístico. $\mathrm{O}$ inverso, isto é, o contingencial será aquilo que estiver situado no espaço verificado na experiência a posteriori, o espaço relativo. Estes situarão as coisas particulares ou singulares dependendo da extensão em que abarquem, ou seja, serão o sítio do gênero ou da espécie, ou ambos simultaneamente. Assim, a Terra se situa num espaço universal e absoluto que a abarca. Ela esta situada numa parte deste espaço uno e indivisível. Na sua relatividade, a Terra em sua espacialidade poderá ser gênero de extensões menores, ou melhor, poderá conter em seu espaço, espaços menores (regiões) onde situarão as espécies ou os gêneros menores e assim por diante.

Uma outra implicação destas posições remete à relação espaço-quantidade e à questão descrição-explicação. A propriedade quantitativa da realidade é vista no processo de apreensão do real no horizonte da descrição. Ou seja, o ato analítico aqui caracteriza-se por ser de classificação desses fenômenos, não transcendendo este patamar. Para isto, veja-se que os aspectos quantitativos do real envolvem, sobretudo, processos enumerativos que se estabelecem no processo de descrição, enquanto etapa da elaboração do conhecimento. Dão conta especialmente do grau, do quanto, do número, das coisas na realidade.

Justifica-se assim o por que do filósofo relacionar o espaço com a categoria de quantidade. Aquantidade estabelece o movimento contínuo do ser num espaço, igualmente contínuo e invariável. $\mathrm{O}$ deslocamento mecânico deve supor a invariância do ser e do espaço onde este se desloca.

Neste sentido é que podemos compreender a razão da designação da tarefa descritiva atribuída à ciência geográfica, isto em função do fato de que o conhecimento em-si das coisas é impossível, e devemos, portanto, nos deter numa apreensão sistemática dos fenômenos. Portanto, se verificará sua variação quantitativa, num deslo- 
camento mecânico, onde a descontinuidade do espaço é um dado empírico derivado de variações quantitativas, o que expressamente, diga-se de passagem, não revela uma verdadeira descontinuidade. $\mathrm{O}$ que se tem, em verdade, é que cada parte do espaço é em si mesmo contínuo, sendo possível apreendê-lo mediante um espaço absoluto, de caráter formal, onde nem as variações quantitativas são verificadas.

\section{LÓGICA E ESPAÇO NA OBRA DE IMMANUEL KANT E SUAS IMPLICAÇÔES NA CIÊN- CIA GEOGRÁFICA}

Resumo: Este trabalho destina-se a verificar a importância e a natureza da categoria espaço, diferentes obras de Immanuel Kant, isto tanto na chamada fase pré-crítica, quanto no período crítico. Com isso permite-se avaliar em detalhes o quanto estas posições foram importantes para os fundamentos epistemológicos da ciência geográfica.

Palavras-chave: Filosofia. Espaço, Kantismo

\section{LOGICAL AND SPACE IN IMMANUEL KANT WORKS AND ITS IMPLICATIONSON GEOGRAPHYCAL SCIENCE.}

Abstract: This work tries to verify the importance and nature of space cathegory. Different works of Immanuel Kant so in pre-critical phase as in the critical period. This allows to estimate in details how these positions have been important for epistemological fundaments on Geographical science.

Key words: Philosophy; Space; Kantism.

\section{BIBLIOGRAFIA}

CASSIRER, Ernest. 1985. Kant, Vida Y Doctrina. México: Fondo de Cultura Económica.

GALEFFI, Romano. 1986. A Filosofia de Immanuel Kant. Brasília: Editora Universidade de Brasilia.

GOLDMANN, L. 1974. Introdución a la Filosofía de Kant. Buenos Aires: Amorrortu editores.

KANT, Immanuel. 1983. Crítica da Faculdade do Juízo. São Paulo: Forense Universitária.

1994. Crítica da Razão Prática. Lisboa: Edições 70.

1985. Crítica da Razão Pura. Lisboa: Fundação Calouste

Gulbenkian.

1992. Lógica. Rio de Janeiro: Tempo Universitário.

. 1990. Princípios Metafísicos da Ciência da Natureza. Lisboa:

Edições 70.

1983. Textos Pré-críticos. Porto: Rés Editorial.

1910. Kant's Gesammelte Schriften. Berlim: Georg Reimer.

LEBRUN, Gérard.1993. Kant e o Fim da Metafísica. São Paulo: Martins Fontes.

. 1993. Sobre Kant. São Paulo: Iluminuras/Edusp.

PASCAL, George. 1985. O Pensamento de Kant. $2^{\mathrm{a}}$ ed. Pertápolis: Vozes. 